\title{
SINALIZAÇÃO ENTRE OS SISTEMAS RADICULARES E CAULINARES EM GENÓTIPOS CONTRASTANTES DE Lycopersicon SOB ESTRESSE POR DEFICIÊNCIA HÍDRICA
}

\author{
OSCAR DARÍo BERMÚDEZ ZAMBRANO
}

\begin{abstract}
Dissertação apresentada à Escola Superior de Agricultura "Luiz de Queiroz", Universidade de São Paulo, para obtenção do título de Mestre em Ciências, Área de Concentração: Fisiologia e Bioquímica de Plantas.
\end{abstract}

P I R A C I C A B A

Estado de São Paulo - Brasil

Abril - 2004 


\title{
SINALIZAÇÃO ENTRE OS SISTEMAS RADICULARES E CAULINARES EM GENÓTIPOS CONTRASTANTES DE Lycopersicon SOB ESTRESSE POR DEFICIÊNCIA HÍDRICA
}

\author{
OSCAR DARÍo BERMÚDEZ ZAMBRANo
}

Licenciado em Biologia

Orientador: Prof. Dr. RICARDO FERRAZ DE OLIVEIRA

Dissertação apresentada à Escola

Superior de Agricultura "Luiz de Queiroz", Universidade de São Paulo, para obtenção do título de Mestre em Ciências, Área de Concentração: Fisiologia e Bioquímica de Plantas.

P I R A C I C A B A

Estado de São Paulo - Brasil

Abril - 2004 

Dados Internacionais de Catalogação na Publicação (CIP)
DIVISÃO DE BIBLIOTECA E DOCUMENTAÇÃO - ESALQ/USP

Bermúdez Zambrano, Oscar Darío

Sinalização entre os sistemas radiculares e caulinares em genótipos contrastantes de Lycopersicon sob estresse por deficiência hídrica / Oscar Darío Bermúdez Zambrano. - - Piracicaba, 2004.

33 p. : il.

Dissertação (mestrado) - - Escola Superior de Agricultura Luiz de Queiroz, 2004.

Bibliografia.

1. Ácido abscísico 2. Deficiência hídrica 3. Estresse vegetal 4. Genótipo 5. Hormônio vegetal 6. Morfologia vegetal 7. Tolerância a seca 8. Tomate I. Título

CDD 635.642

"Permitida a cópia total ou parcial deste documento, desde que citada a fonte - O autor" 
À memoria de meu pãe Luis Antonio

À minha mãe Emelina

Às minhas irmãs Martha Lucía, Alba Nery e Gloria Inés

Aos meus sobrinhos German Oliver e Carlos Adan,

pelo amor e a motivação para recorrer este caminho.

DEDICO 


\section{AGRADECIMENTOS}

A Deus pela sua infinita bondade que me permitiu converter em realidade este sonho.

À Universidad Nacional de Colombia pela licença para realizar meus estudos de pós-graduação.

À Escola Superior de Agricultura “Luiz de Queiroz”, Universidade de São Paulo, por abrir suas portas para meu aperfeiçoamento profissional e pessoal.

Ao Prof. Dr. Ricardo Ferraz de Oliveira, pela orientação, confiança e paciência no decorrer do curso.

Ao Prof. Dr. Lázaro Eustaquio Pereira Peres, pela orientação, confiança e constante incentivo durante a realização deste trabalho.

Aos professores Beatriz Appezzato-da-Glória e Murilo de Melo, pela compreensão e apoio durante a realização do curso.

A Cilia Leonor Fuentes professora da Universidad Nacional de Colombia pelo apoio incodicional e incentivo para realizar meus estudos de mestrado.

A Constanza Cabrera pela generosa e permanente colaboração.

A Soraya França e Raf De Vis pela amizade, hospitalidade e por amenizar a ausência da minha familia

A Rafael Vasconcelos Ribeiro e Mauro Guida dos Santos pela amizade e preciosa colaboração durante a realização deste trabalho. 
Aos meus colegas de trabalho, Paula Carolina de Simoni Cordeiro, Míriam Ferraz Moreira, Gustavo Maia Souza, Marcelo Ribeiro Romano, Camila do Prado Cenciani pela amizade e por fazer agradável minha estadia no laboratório.

A Maria Solizete Granziol Silva Secretaria do curso de Pós-Graduação em Fisiologia e Bioquímica de Plantas, pela paciência, compreensão e permanente disponibilidade em me ajudar.

Aos funcionários do Departamento de Ciências Biológicas especialmente a José Francisco Rodrigues e Francisco Xavier Vitti , pelo apoio técnico.

À bibliotecária Silvia Zinsly, pela revisão de editoração e formatação final deste documento.

A Vera Lucía Avila, pelo amor, compreensão e permanente apoio.

A Carolina e Andrea Avila Cisotto pela amizade e convivência

A Vera María Sacon pela amizade e energia positiva para que tudo saira do melhor jeito.

A Nora Mesa, Isabel Zuluaga e Adriana Castellanos, pelos gestos de solidaridade

A os funcionários da biblioteca da Escola Superior de Agricultura "Luiz de Queiroz”-USP pela amabilidade e serviço oportuno

Ao pessoal de apoio do serviço de pós-graduação da Escola Superior de Agricultura “Luiz de Queiroz”-USP, pela valiosa colaboração.

A todas as pessoas que de alguma forma contribuíram para a realização deste trabalho. 
SUMÁRIO

Página

LISTA DE ABREVIATURAS E SÍMBOLOS viii

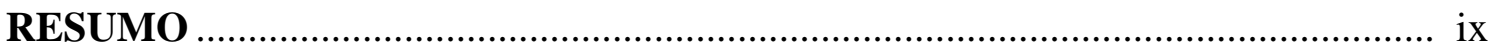

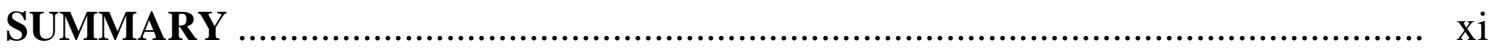

1 INTRODUÇÃO

2 REVISÃO DE LITERATURA ……………………..........................................

2.1 LYCOPERSICON PENNELLII COMO ESPÉCIE SILVESTRE TOLERANTE A SECA .......... 3

2.2 BIOSSÍNTESE DO ÁCIDO ABSCÍSICO .............................................................. 4

2.3 MutANTES DE TOMATEIRO COM ALTERAÇõES NA BIOSSÍNTESE DE ÁCIDO

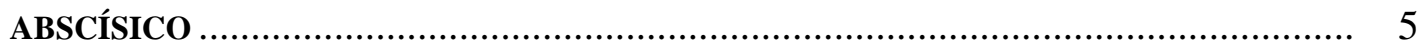

2.4 O ÁCIDO ABSCÍSICO COMO SINALIZADOR HORMONAL ENTRE RAIZ E CAULE.......... 6

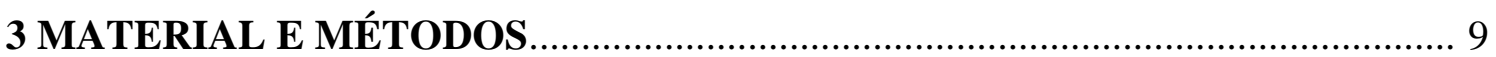

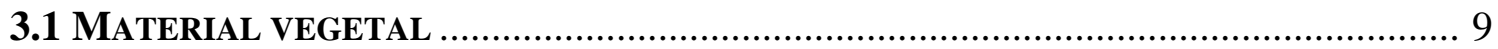

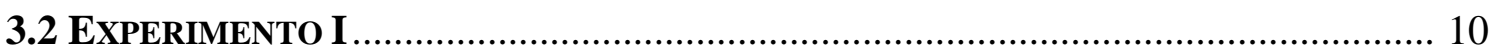

3.2.1 Medição da condutância estomática e transpiração …………………………... 10

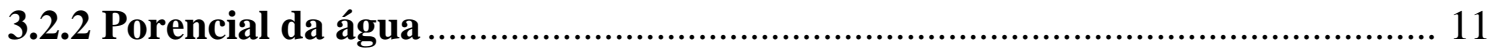

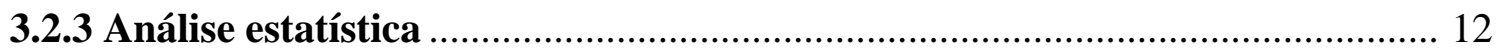

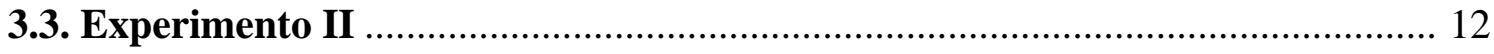

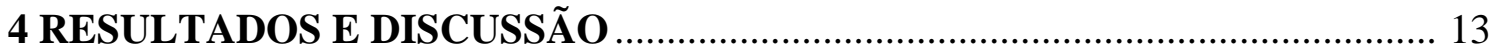




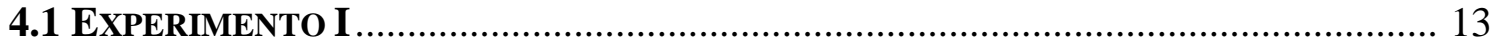

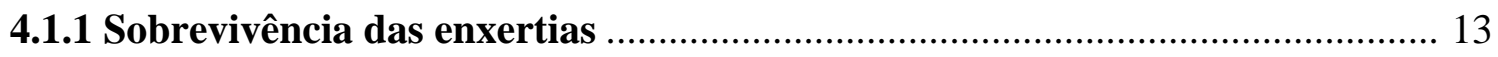

4.1.2 Condutância estomática e transpiração ................................................... 14

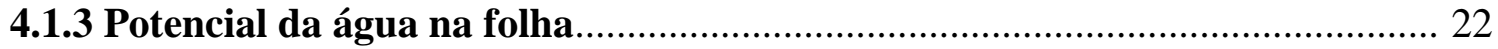

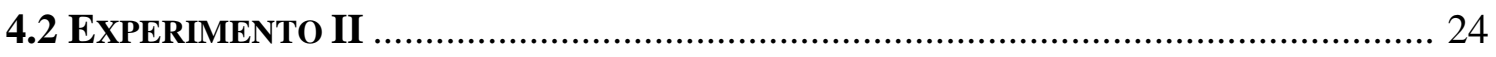

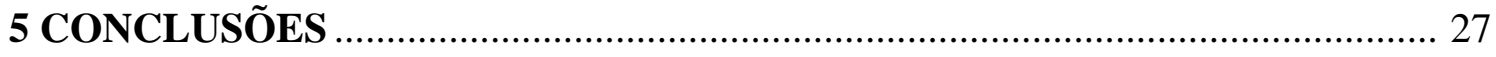

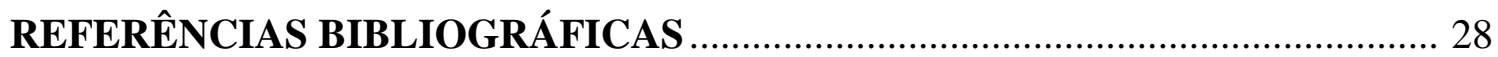




\section{LISTA DE ABREVIATURAS E SÍMBOLOS}
ABA
ácido abscísico
DFFF
densidade de fluxo de fótons fotossintéticos $\left(\mu \mathrm{mol} \mathrm{m}{ }^{-2} \mathrm{~s}^{-1}\right)$
$\mathbf{D P V}_{\text {f-ar }}$
déficit de pressão de vapor entre a folha e o ar $(\mathrm{kPa})$
IRGA
analisador de gases por infra-vermelho
Lukullus
Lycopersicon esculentum cv Lukullus
Luk/Luk
enxertia com copa Lukullus e porta-enxerto Lukullus
Luk/not
enxertia com copa Lukullus e porta-enxerto notabilis
Luk/pen
enxertia com copa Lukullus e porta-enxerto pennellii
notabilis
mutante notabilis de L. esculentum
not/not
enxertia com copa notabilis e porta-enxerto notabilis
not/Luk
enxertia com copa notabilis e porta-enxerto Lukullus
pennellii
Lycopersicon pennellii
pen/pen
enxertia com copa pennellii e porta-enxerto pennellii
pen/Luk
enxertia com copa pennellii e porta-enxerto Lukullus
pen/not
enxertia com copa pennellii e porta-enxerto notabilis
$\Psi_{\mathrm{f}}$
potencial da água na folha (-MPa) 


\title{
SINALIZAÇÃO ENTRE OS SISTEMAS RADICULARES E CAULINARES EM GENÓTIPOS CONTRASTANTES DE Lycopersicon SOB ESTRESSE POR DEFICIÊNCIA HÍDRICA
}

\author{
Autor: OSCAR DARÍO BERMÚDEZ ZAMBRANO \\ Orientador: Prof. Dr.: RICARDO FERRAZ DE OLIVEIRA
}

\section{RESUMO}

Como organismos multicelulares complexos, as plantas requerem um extraordinário nível de coordenação entre as células para que se desenvolvam ordenadamente. Para a coordenação dessas atividades, as células devem freqüentemente ser aptas a se comunicar umas com as outras a certas distâncias. Os principais meios de comunicação intercelular são os hormônios e mensageiros químicos que carreiam as informações entre as células e assim coordenam seu crescimento e desenvolvimento. O ácido abscísico (ABA) é o hormônio envolvido nos processos fisiológicos quando as plantas são expostas a alguns tipos de estresse, como deficiência hídrica. Relativamente grandes quantidades de ABA são rapidamente sintetizadas em folhas em resposta ao estresse hídrico, onde o principal papel parece ser a regulação da abertura e fechamento estomático. No início do estresse hídrico, o ABA carreado pelo fluxo xilemático é sintetizado nas raízes que estão em contato direto com o solo seco. Devido a esse 
transporte poder ocorrer antes que o baixo potencial de água no solo cause qualquer mudança mensurável no estado hídrico das folhas, acredita-se que o ABA seja um sinal das raízes que ajuda a reduzir a taxa de transpiração nas folhas pelo fechamento estomático. O principal objetivo do trabalho foi determinar se o ABA sintetizado nas raízes de Lycopersicon esculentum é crucial na regulação do comportamento estomático ou se o ABA produzido pelas folhas poderia agir como sinal hormonal que permitisse a sobrevivência da planta em condições de deficiência hídrica. De forma similar, Lycopersicon pennellii, uma espécie tolerante ao estresse hídrico, foi estudada com o objetivo de determinar a possível função dos sinais químicos das raízes ou de outro mecanismo de tolerância a seca. Para tanto, plantas com 30 dias de idade obtidas de sementes de L. esculentum cv Lukullus, L. pennellii e um mutante chamando notabilis foram enxertadas umas nas outras e crescidas em casa de vegetação. Após dois meses, medidas de condutância estomática, transpiração e potencial da água na folha foram realizadas em três condições de água no solo: bem irrigado, estresse hídrico e reirrigação. Os valores de condutância estomática e transpiração mostraram que o comportamento estomático foi determinado pelo genótipo da parte aérea das plantas enxertadas. Também verificou-se que a tolerância a seca em L. pennellii não foi determinada exclusivamente por caracteres morfo-anatômicos da parte aérea. 


\title{
ROOT-SHOOT COMMUNICATION IN CONTRASTING Lycopersicon GENOTYPES UNDER STRESS CAUSED BY WATER DEFICIT
}

\author{
Author: OSCAR DARÍO BERMÚDEZ ZAMBRANO
}

Adviser: Prof. Dr.: RICARDO FERRAZ DE OLIVEIRA

\section{SUMMARY}

Multicellular plants are complex organisms and their orderly development requires an extraordinary measure of coordination between cells. In order to coordinate their activities, cells must be able to communicate with each other, often at some distance. The principal means of intercellular communication are the hormones, chemical messengers that carry information between cells and thus coordinate their growth and development. Abscisic acid (ABA) is the hormone involved in physiological processes when plants are exposed to some sort of stress: water deficiency, for example. Relatively large amounts of ABA are rapidly synthesized in leaves in response to water stress, where it appears to play a major role in regulating stomatal opening and closure. As water stress begins, some of the ABA carried out by the xylem stream is synthesized in roots that are in direct contact with the drying soil. Because this transport can occur before the low water potential of the soil causes any measurable change in the water status of the leaves, ABA is believed to be a root signal that helps reduce the 
transpiration rate in the leaves by closing stomata. The main objective of the work was to determine if ABA synthesized in the roots of Lycopersicon esculentum is crucial in regulation stomata behavior or ABA produced by the leaves could act as hormone signal to improve plant survival under water shortage conditions. In a similar way, Lycopersicon pennellii, a water stress tolerant specie, was studied in order to determine the possible role of chemical root signals or any other mechanism. For that, $30 \mathrm{~d}$-old plants obtained from seeds of L. esculentum cv Lukullus, L. pennellii and a mutant named notabilis were grafted to each other and grown in greenhouse conditions. Two months later, measurements of stomatal conductance, transpiration and leaf water potential were carried out. These measurements were done under three soil water conditions: plenty, stress and reirrigation. The values of stomatal conductance and transpiration showed that stomatal behavior was influenced by the genotype of the aerial part of grafted plants. It was also verified that the drought tolerance of $L$. pennellii was not only determined by morpho-anatomical characteristics of plant shoot. 


\section{INTRODUÇÃO}

As plantas superiores, como organismos multicelulares complexos, precisam de uma extraordinária coordenação entre suas partes. Para isto é necessária a existência de meios de comunicação que facilitem o transporte de sinais, muitas vezes a longas distâncias. Os principais meios sinalizadores são os hormônios, mensageiros químicos que permitem às plantas estabelecerem comunicação entre suas diferentes estruturas e o ambiente onde elas se encontram.

Em qualquer lugar que as plantas cresçam, estão sujeitas às condições de múltiplos estresses, os quais limitam seu desenvolvimento e suas chances de sobrevivência. Nestas circunstâncias os hormônios desempenham um importante papel na percepção de estímulos desfavoráveis do meio ambiente e na geração de respostas adequadas que garantam a sobrevivência das plantas.

O hormônio mais estudado em relação ao estresse originado por deficiência de água é o ácido abscísico (ABA). Em geral, é reconhecido que as plantas submetidas a carências hídricas no solo produzem altos níveis de ABA na raiz, o qual é transportado via xilema para a parte aérea da planta onde atua como sinal de transdução que promove o fechamento estomático, evitando desta forma a perda excessiva de água por transpiração (Davies e Zhang, 1991). No entanto, este mecanismo de resposta tem efeitos negativos na fotossíntese, já que o fluxo de $\mathrm{CO}_{2}$ e água ocorre em direção oposta e pela mesma via.

A existência de mutantes deficientes em ABA permite estudar a importante função que o ABA desempenha no comportamento fisiológico das plantas. Notabilis (not) é um mutante do tomateiro (Lycopersicon esculentum Mill) que, sob condições de estresse hídrico, apresenta transpiração excessiva, devido ao fato da quantidade de ABA 
sintetizado por ele ser insuficiente para provocar o fechamento estomático (Neill e Horgan, 1985). Por outro lado, dentro do gênero Lycopersicon há a espécie L. pennellii que se destaca por sua tolerância ao déficit hídrico. Segundo dados da literatura este atributo é conseqüência de características morfo-anatómicas que impedem a perda excessiva de água por transpiração (Kebede et al. 1994).

O presente trabalho teve como objetivos: determinar se o ABA sintetizado na raiz é indispensável na regulação do comportamento estomático de $L$.esculentum ou o ABA produzido na parte aérea da planta pode atuar como sinal hormonal que facilita a sobrevivência da planta em condições de estresse por deficiência hídrica.

Além disso, procurou-se estabelecer se em L. pennellii a tolerância a seca está determinada por caracteres morfo-anatômicos no caule ou sinais hormonais provenientes da raiz. 


\section{REVISÃO DE LITERATURA}

\subsection{Lycopersicon pennellii como espécie silvestre tolerante a seca}

O gênero Lycopersicon abrange nove espécies silvestres: L. esculentum var cerasiforme (Dun.) Gray, L. pimpinellifolium (Jusl.) Mill., L. cheesmanii Riley, L. parviflorum Rick, Kes., Fob., \& Holle., L. chmmielewskii Rick, Kes., Fob., \& Holle., L. hirsutum Humb. \& Bonpl., L. peruvianum (L.) Mill., L. chilense Dun., e L. pennellii D’Arcy (Taylor, 1986).

A distribuição natural do gênero Lycopersicon se estende desde o norte do Chile até o sul do Equador e da Costa do Pacífico (incluídas as ilhas Galápagos) até a Cordilheira dos Andes (Esquinas-Alcazar e Nuez, 2001). A extensa distribuição geográfica deste gênero lhe permite ocupar diferentes habitats e experimentar diversas condições ambientais, o que contribui para sua variabilidade genética (Warnock, 1988).

O habitat natural de $L$. pennellii corresponde à região localizada desde o oriente dos Andes peruanos até o oeste da Costa Pacífica, caracterizada por ser quente e seca, condições que fazem que $L$. pennellii seja naturalmente tolerante a seca (Taylor, 1986).

L. pennellii apresenta uma freqüência estomática $29 \%$ menor, suas folhas são 54\% mais espessas, com espaços aéreos equivalentes a 31\% do volume relativo ao total do volume de tecido foliar comparado com L. esculentum. Porem, L. pennellii contêm $13 \%$ menos clorofila e uma atividade da ribulose-1,5 bifosfatocarboxilase/oxigenase (Rubisco) 11\% menor por unidade de área foliar do que L. esculentum (Kebede et al., 1994). Estes fatores parecem indicar que L. pennellii possui adaptações morfoanatômicas para evitar a perda de água, bem como mecanismos para compensar o déficit de $\mathrm{CO}_{2}$ absorvido. 
Torrecillas et al. (1995) observaram que em plantas de L. pennellii sob condições de estresse hídrico não aconteciam mudanças morfológicas como aquelas que ocorriam em $L$.esculentum, como diminuição da área e suculência foliar. Além disso, sintomas de murchamento nesta última espécie indicam uma grande suscetibilidade de plantas de espécies domesticadas, quando são submetidas a períodos curtos de déficit hídrico. L. pennellii conservou os estômatos fechados por 6 dias depois de voltar a receber água constituindo este fato um possível mecanismo de proteção que permite à planta recobrar o turgor mais prontamente. Plantas de L. esculentum apresentaram aumento na condutância estomática logo depois do fornecimento de água, indicando que um mecanismo hidropassivo está controlando diretamente a abertura estomática, enquanto em L.pennellii o estado hídrico da folha não parece ser o único fator que controla a abertura estomática. A demora em recobrar a abertura estomática depois da reidratação das plantas tem sido atribuída ao efeito persistente do ácido abscisico produzido durante o período de estresse hídrico (Fisher et al., 1970).

\subsection{Biossíntese do ácido abscísico}

O ABA é um sesquiterpenóide (composto de 15 carbonos) formado a partir da unidade C5 comum dos terpenos, o isopentenilpirofosfato (IPP), sintetizado parcialmente nos cloroplastídios e outros plastídios (Taiz e Zeiger, 1998). A conversão de zeaxantina ao epoxicarotenoide violaxantina catalisada pela enzima zeaxantina epoxidase (ZEP) é considerada o primeiro passo na biossíntese de ABA (Zeevaart e Creelman, 1988; Thompson et al., 2000). Nessa etapa são produzidas duas formas isoméricas 9-cis-violaxantina e 9'-cis-neoxantina, sendo esta última o substrato mais provável sobre o qual atua a 9-cis-epoxicarotenóide dioxigenase (NCED) para sua conversão mediante quebra oxidativa em cis-xantoxina, composto de 15 átomos de carbono precursor do ABA. Depois, no citosol a cis-xantoxina é convertida a aldeido abscísico, que em reação catalisada pela enzima aldeido abscísico oxidase (AAO) é convertido finalmente a ABA (Bray, 2002). 


\subsection{Mutantes de tomateiro com alterações na biossíntese de ácido abscísico}

Flacca ( flc), sitiens (sitiens) e notabilis (not) são mutações pontuais recessivas de tomateiro produzidas por tratamento com raios X. Mesmo estas mutações tendo ocorrido em alelos de três loci separados, estes mutantes comportam-se de forma similar em condições de estresse hídrico. Quando plantas mutantes e normais são submetidas a estresse por deficiência hídrica os mutantes murcham primeiro, como conseqüência de transpiração excessiva. Este murchamento característico é expressado pelos mutantes em todos os estágios de vida. Sendo interessante destacar que eles têm mais estômatos por unidade de superfície foliar que o tipo não mutante. Esta maior freqüência de estômatos nos mutantes pode ser resultado de uma extensiva diferenciação de mais estômatos ou simplesmente é decorrente do reduzido tamanho das folhas nestas plantas. Também temse observado que muitos estômatos dos mutantes permanecem abertos no escuro o que explicaria sua alta taxa de transpiração na noite, comparada com a taxa observada no tipo não mutante (Tal, 1966).

Geralmente, considera-se que a pressão de turgor das células guarda é um importante fator no comportamento dos estômatos. Contudo, os resultados dos estudos feitos por Tal (1966) mostram que a pressão de turgor sozinha não controla a abertura estomática nos mutantes flacca, sitiens e notabilis, já que os estômatos de plantas dos três mutantes permanecem abertos no escuro, em folhas murchas e em folhas tratadas com acetato de fenilmercúrio, condições estas que causam fechamento estomático em plantas normais.

A oxidação do aldeído de ABA está bloqueada nos mutantes de tomateiro flacca (flc) e sitiens (sit). Estes mutantes quando são submetidos a estresse hídrico acumulam 2-trans-ABA álcool ao envés de ABA (Linforth et al., 1987). Isto indica que as enzimas associadas com a formação da estrutura do anel de ABA são completamente funcionais nestes dois mutantes. O defeito genético consiste na incapacidade para sintetizar uma enzima que catalise a oxidação da cadeia lateral do ABA aldeído e forme o grupo carboxílico do ácido (Parry et al., 1988). A perda na atividade da AAO pode resultar de uma mutação na apoproteína aldeído oxidase ou lesão na síntese de um 
cofator (MoCo) necessário para ativá-la. Este último fato, parece causar em flacca a falta de atividade aldeído oxidase (Keith, 2000; Schwartz et al., 2003). Resultados de estudos empregando ${ }^{18} \mathrm{O}$ nestes mutantes, têm permitido descobrir uma rota alternativa menor, pela qual o álcool de ABA e o 2-trans-ABA álcool se convertem a ABA e 2trans-ABA por ação de uma mono-oxigenase dependente do sistema P-450 do citocromo (Rock et al., 1991). De maneira diferente, o impedimento na biossíntese de ABA no mutante notabilis consiste em um bloqueio enzimático que impede a quebra oxidativa do carotenoide 9' -cis-neoxantina para originar a xantoxina (Duckham et al., 1989).

\section{$2.4 \mathrm{O}$ ácido abscísico como sinalizador hormonal entre raiz e caule}

Existem evidências indicando que a sinalização hormonal é importante na regulação de respostas do caule (Davies e Zhang, 1991), e o ABA como promotor de fechamento estomático (Jones e Mansfield, 1970; Assmann e Shimazaki, 1999), tem sido indicado em particular como um importante sinal químico gerado na raiz e enviado ao caule, via xilema. O ABA desempenha um importante papel no processo de sinalização a longa distância em plantas sob condições de déficit hídrico (Gowing et al., 1990; Davies e Zhang, 1991).

O ABA tem uma dupla função na proteção das plantas frente ao estresse hídrico. A curto prazo reduz a transpiração, e a longo prazo induz a síntese de proteínas que aumentam a tolerância da planta à dessecação (Azcon-Bieto e Talon, 1996). Depois da aplicação de ABA nas folhas, os estômatos fecham-se prontamente (Cummins et al., 1971). Este fechamento se deve à perda da turgescência das células guarda, devido ao fato de que íons $\mathrm{K}^{+}, \mathrm{Cl}^{-}$e malato migram desde as células guarda para as células vizinhas (Hetherington e Quatrano, 1991).

Quando as folhas experimentam estresse hídrico, a biossíntese do ABA se induz por perda da turgescência. No entanto, os estômatos geralmente se fecham antes que ocorra aumento do ABA na folha. Harris e Outlaw (1991) determinaram o conteúdo do ABA em diferentes tipos celulares e encontraram que a concentração do ABA das células guarda de Vicia faba aumentava consideravelmente ( 9 vezes) antes que se 
incrementasse o ABA em outros tipos celulares. O ABA pode ser sintetizado nas células guarda ou pode ser o resultado da redistribuição do ABA dentro da folha devido à influência do estresse. As células guarda não se comunicam com as células vizinhas mediante plasmodesmas, e o ABA somente pode chegar via apoplasto. O local de ação do ABA nas células guarda localiza-se na superfície do plasmalema destas células (Hartung, 1983). Isto significa que não é a concentração no interior das células, mas a concentração do ABA no apoplasto que rodeia as células guarda o fator que regula o fechamento estomático (Azcon-Bieto e Talon, 1996).

O ABA é considerado uma sinal proveniente da raiz que ajuda a reduzir a transpiração nas folhas por fechamento dos estômatos. Sob condições de estresse hídrico, o conteúdo de ABA nas folhas pode incrementar até 50 vezes entre 4 a 8 horas. Com a rehidratação a concentração de ABA volta ao nível normal na mesma velocidade. O ABA é transportado pelo xilema e floema, mas a quantidade é maior na seiva do floema. Quando começa o estresse hídrico, uma quantidade do ABA transportado pela corrente xilemática é sintetizado nas raízes que estão em contato direto com o solo seco. Este transporte pode ocorrer antes que o potencial da água do solo cause alguma mudança mensurável no estado hídrico das folhas (Davies e Zhang, 1991).

Stuart et al., (1997) sugeriram que uma forma pela qual o estresse por deficiência hídrica poderia modificar a concentração de ABA no apoplasto e, deste modo, a sensitividade dos estomatos ao ABA presente na corrente xilemática, seria mudando o pH deste compartimento. Em plantas que se encontram em condições ótimas de irrigação, o apoplasto possui um $\mathrm{pH}$ aproximadamente 1,5 unidades mais ácido do que o intracelular. O ABA é um composto fracamente ácido que se apresenta na forma não dissociada (protonado) como $\mathrm{ABAH}$, forma na qual pode-se difundir através da membrana plasmática para o interior da célula, deixando de estar disponível no apoplasto para que ocorra o fechamento estomático (Davies et al., 2002).

Embora uma concentração de 3,0 $\mu \mathrm{M}$ de ABA no apoplasto seja suficiente para fechar os estômatos, nem todo o ABA da corrente xilemática alcança as células guarda. Parte do ABA é arrastado na corrente transpiratória e metabolizado pelas células do mesofilo. Durante o estado inicial de estresse por deficiência hídrica o pH da seiva do 
xilema aumenta aproximadamente de 6,3 para 7,2 (Wilkinson e Davies, 1997). A alcalinização do apoplasto favorece a produção de formas dissociadas de ABA, as quais não podem atravessar a membrana plasmática facilmente. Portanto, menos ABA entra nas células do mesofilo e mais atinge as células guarda via corrente transpiratória. $\mathrm{O}$ ABA é redistribuído na folha desta maneira sem incremento no nível de ABA total (Taiz e Zeiger, 1998).

Por fim é importante ressaltar que existem dois mecanismos envolvidos no fechamento estomático, um hidropassivo e outro hidroativo. Ao contrário das células epidérmicas, as superfícies das células guardas não são protegidas por uma cutícula espessa. Conseqüentemente, as células guardas perdem água diretamente para a atmosfera. Se a taxa de perda de água for maior que a reposição pelas células ao redor, a célula ficará flácida e os estômatos fecharão. Esse tipo de fechamento é denominado hidropassivo. O fechamento hidroativo é dependente do metabolismo e envolve saída de solutos. O papel do ABA no mecanismo hidroativo é justamente controlar a saída de solutos. O principal soluto envolvido é o potássio, sendo que o ABA inibe um canal de influxo desse íon através da inibição da atividade da $\mathrm{H}^{+}$-ATPase. Essa inibição da atividade da $\mathrm{H}^{+}$-ATPase, por sua vez, é mediada pelo $\mathrm{Ca}^{2+}$, como mensageiro secundário. Além de inibir o canal de entrada de $\mathrm{K}^{+}$, o ABA também ativa o canal de saída de $\mathrm{K}^{+}$através da alcalinização do citosol (o pH passa de 7,6 para 7,9). Desse modo, a diminuição da concentração de $\mathrm{K}^{+}$na célula guarda leva a um aumento do potencial osmótico (torna-se menos negativo). À medida que o potencial osmótico aumenta, o potencial hídrico também aumenta provocando a saída de água na célula e consequente fechamento estomático (Taiz e Zeiger, 1998). 


\section{MATERIAL E MÉTODOS}

Para a realização do presente trabalho foi necessário fazer dois experimentos, o primeiro deles foi instalado na casa de vegetação do Laboratório de Plantas Cultivadas Sob Condições de Estresse do Departamento de Ciências Biológicas, da Escola Superior de Agricultura “Luiz de Queiroz”/USP, em Piracicaba/SP.

\subsection{Material vegetal}

Sementes de L. esculentum cv Lukullus, L. pennellii e do mutante notabilis de L. esculentum o qual é isogênico a Lukullus, foram semeadas em bandejas plásticas. Quinze dias depois de germinadas, as plântulas foram transplantadas para vasos plásticos de 8 litros, contendo 3,5 kg de substrato(composto por uma mistura de 90\% Plantmax e 10\% vermiculita expandida), adubado a cada duas semanas com uma fonte de nitrogênio, fósforo e potássio (N-P-K), contendo 10\% de cada nutriente.

Tabela 1. Enxertias obtidas mediante a combinação dos sistemas radiculares e caulinares dos genótipos Lycopersicon esculentum cv Lukullus (Luk), L. esculentum mutante notabilis (not) e L. pennellii (pen).

\begin{tabular}{cccccccccc}
\hline Tratamento & 1 & 2 & 3 & 4 & 5 & 6 & 7 & 8 & 9 \\
\hline Copa & Luk & Not & pen & not & Luk & pen & pen & Luk & not \\
Porta-enxerto & Luk & Luk & Luk & not & not & not & pen & pen & pen \\
\hline
\end{tabular}

Transcorridos 30 dias depois do transplante foram feitas enxertias recíprocas do tipo fenda cheia, nas combinações porta-enxerto copa como descrito na tabela 1. Para 
aumentar a umidade relativa e reduzir a perda de água por transpiração, as enxertias permaneceram cobertas com garrafas plásticas transparentes durante doze dias.

Todos os brotos florais foram eliminados para que as plantas se mantivessem no estado vegetativo. Do mesmo modo, todas as ramificações laterais foram eliminadas para facilitar a condução das plantas.

A irrigação foi praticada diariamente no final da tarde até que o substrato atingisse a capacidade de campo, prevenindo-se a ocorrência de estresse hídrico antes da imposição experimental de deficiência hídrica.

\subsection{Experimento I}

\subsubsection{Medição da condutância estomática e transpiração}

Após sessenta dias de realizadas as enxertias, em folhas completamente expandidas, localizadas no terço médio da planta, foram feitas diariamente medições de condutância estomática e transpiração, empregando para isto um analisador de gases por infra-vermelho (Li-6400, LiCor, EUA). As condições em que foram feitas as medições encontram-se descritas na Tabela 2.

Durante o período das medições, as plantas permaneceram por quatro dias sob condições normais de disponibilidade hídrica e no quinto dia três plantas de cada enxertia foram submetidas a deficiência hídrica, mediante suspensão da irrigação. Para evitar a perda de água do substrato por evaporação, a superfície dos vasos foi coberta com papel alumínio.

O tempo de imposição da deficiência hídrica foi de três dias nas enxertias not/not, not/Luk, Luk/not e pen/not, enquanto as enxertias Luk/Luk, pen/pen, Luk/pen e pen/Luk foram submetidas a deficiência hídrica por sete dias.

Como controle, foram mantidas três plantas sempre irrigadas das enxertias Luk/Luk, pen/Luk, Luk/not e pen/not, entretanto das enxertias not/not, not/Luk, pen/pen e Luk/pen, não foi possível manter plantas como controle devido a baixa porcentagem de sobrevivência dessas enxertias (Tabela 3). 
Tabela 2. Valores da diferença de pressão de vapor entre folha e ar (DPV $\left.\mathrm{f}_{\text {-ar }}\right)$, temperatura do ar $\left(\mathrm{T}_{\mathrm{ar}}\right)$ e foliar $\left(\mathrm{T}_{\text {folha }}\right)$ e densidade de fluxo de fótons fotossintéticos (DFFF) durante as medidas de condutância estomática e transpiração

\begin{tabular}{|c|c|c|c|c|}
\hline Dia & $\mathrm{DPV}_{\mathrm{f} \text {-ar }}(\mathrm{kPa})$ & $\mathrm{T}_{\mathrm{ar}}\left({ }^{\circ} \mathrm{C}\right)$ & $\mathrm{T}_{\text {folha }}\left({ }^{\circ} \mathrm{C}\right)$ & DFFF $\left(\mu \mathrm{mol} \mathrm{m} \mathrm{m}^{-2} \mathrm{~s}^{-1}\right)$ \\
\hline 1 & 3,23 & 33,31 & 29,83 & 850 \\
\hline 2 & 3,84 & 36,60 & 31,29 & 1000 \\
\hline 3 & 3,93 & 36,90 & 33,61 & 700 \\
\hline 4 & 4,39 & 37,24 & 33,80 & 1000 \\
\hline 5 & 5,40 & 39,12 & 33,82 & 950 \\
\hline 6 & 5,63 & 41,35 & 34,41 & 1000 \\
\hline 7 & 6,95 & 42,90 & 34,91 & 1100 \\
\hline 8 & 4,43 & 36,51 & 35,31 & 800 \\
\hline 9 & 3,84 & 33,36 & 36,28 & 200 \\
\hline 10 & 1,80 & 29,89 & 36,70 & 500 \\
\hline 11 & 3,45 & 37,49 & 36,72 & 1000 \\
\hline 12 & 3,57 & 34,81 & 37,16 & 1000 \\
\hline 13 & 3,62 & 33,66 & 38,61 & 1000 \\
\hline 14 & 4,57 & 36,81 & 39,51 & 1000 \\
\hline 15 & 5,03 & 40,35 & 40,19 & 1000 \\
\hline 16 & 4,45 & 40,47 & 42,15 & 1000 \\
\hline
\end{tabular}

Após o período de deficiência hídrica as plantas foram novamente irrigadas e feitas as medições de condutância estomática até que as plantas alcançaram valores similares aos iniciais.

\subsubsection{Potencial da água}

O estado hídrico das plantas enxertadas foi avaliado diariamente antes do amanhecer, mediante amostragem de seções de lâmina foliar de 7,0 mm de diâmetro, as quais foram colocadas em câmaras psicrométricas (Wescor C-52) acopladas a um 
microvoltímetro (WESCOR HR-33T). As amostras permaneceram no laboratório a $25^{0} \mathrm{C}$ até que pressão de vapor da água da câmara e da amostra alcançaram o equilíbrio, neste momento foi realizada a medição do potencial da água no tecido foliar. As medições estiveram distribuídas no tempo de maneira igual às de condutância estomática e transpiração. Por limitação no número de câmaras psicrométricas foi avaliada somente uma amostra de tecido foliar de cada enxertia.

\subsubsection{Análise estatística}

Os dados correspondentes a condutância estomática e transpiração foram submetidos a análise de variância (ANOVA) e as médias comparadas pelo teste de Tukey a 5\% de probabilidade.

\subsection{Experimento II}

Devido à falta de sucesso na enxertia not/pen, foi realizado um ensaio na casa de vegetação do Laboratório do Controle Hormonal do Desenvolvimento Vegetal. Neste ensaio utilizaram-se plantas de notabilis, L. pennellii e plantas provenientes da enxertia notabilis como parte aérea e $L$. pennellii como porta-enxerto. $\mathrm{O}$ material vegetal foi obtido seguindo a metodologia empregada no primeiro ensaio.

Para melhorar a sobrevivência das enxertias, 24 horas antes de sua realização foi feita uma aplicação foliar de ABA $(10 \mu \mathrm{M})$ nas plantas de notabilis. Este tratamento foi repetido quatro e oito dias depois da realização das enxertias.

A solução de ABA empregada para aplicação foliar foi preparada em água destilada, dissolvendo inicialmente o hormônio com gotas de hidróxido de potássio (KOH) $0,1 \mathrm{M}$.

Plantas com sessenta dias de enxertadas e plantas de notabilis e L. pennellii com a mesma idade, obtidas a partir de sementes, foram submetidas a deficiência hídrica imposta por suspensão da irrigação, avaliando-se o tempo gasto para alcançar a murcha permanente. 


\section{RESULTADOS E DISCUSSÃO}

\subsection{Experimento I}

\subsubsection{Sobrevivência das enxertias}

Conforme mostra a Tabela 3, a sobrevivência das enxertias foi influenciada pelo genótipo tanto da parte aérea como da raiz. Enxertias com o genótipo L. pennellii como porta-enxerto ou notabilis como copa apresentaram baixa sobrevivência. Vale salientar que a enxertia not/pen não teve sucesso e de maneira surpreendente a enxertia pen/not apresentou uma sobrevivência de 100\%.

Tabela 3. Sobrevivência de enxertias entre os genótipos Lycopersicon esculentum cv Lukullus (Luk), L. esculentum mutante notabilis (not) e L. pennellii (pen)

\begin{tabular}{cc}
\hline Tratamento & \% de sobrevivência* \\
\hline Luk/Luk & 66,7 \\
Luk/not & 83,3 \\
Luk/pen & 41,7 \\
pen/pen & 25 \\
pen/Luk & 66,7 \\
pen/not & 100 \\
not/not & 25 \\
not/Luk & 25 \\
not/pen & 0 \\
\hline
\end{tabular}

* 12 enxertias foram feitas em cada tratamento. 
Considerando que notabilis é deficiente na síntese de $A B A$ e que este é necessário para uma apropriada regulação estomática, os resultados parecem indicar que as enxertias com este genótipo como parte aérea apresentaram uma perda excessiva de água por transpiração, o que poderia ser a causa de pouco sucesso. Em experimentos realizados com L. esculentum em enxertia com mutantes deficientes em ABA, Jones et al. (1987), Cornish e Zeevaart (1988) e Holbrook et al. (2002) também obtiveram resultados semelhantes.

Lagrimini et al. (1997) avaliando as conseqüências da super-expressão de peroxidase em plantas transgênicas de tabaco, observaram que enxertias de plantas não transformadas com transgênicas como porta-enxerto não tiveram sucesso, enquanto enxertias de plantas transformadas sobre plantas não transformadas alcançaram uma sobrevivência de $75 \%$. De igual forma, estes autores encontraram um alto nível de expressão de peroxidase no sistema radicular das plantas transgênicas. Em concordância com este resultado, é possível que alguma substância sintetizada na raiz de L. pennellii incidiu de maneira negativa no sucesso das enxertias com este genótipo como portaenxerto. A falta de sucesso na enxertia not/pen pode ser devido ao efeito desfavorável causado tanto pela parte aérea como pelo sistema radicular

\subsubsection{Condutância estomática e transpiração}

O emprego da técnica de enxertia neste experimento permitiu avaliar o comportamento estomático em plantas diferentes com relação a capacidade e local de síntese de ABA. Enxertias com raiz deficiente na síntese de ABA (Luk/not), parte aérea deficiente na síntese de $\mathrm{ABA}$ (not/Luk), tanto raiz como parte aérea deficiente na síntese de ABA (not/not) e com capacidade de síntese de ABA na raiz e parte aérea (Luk/Luk) apresentaram diferenças no controle estomático e na transpiração.

O padrão de resposta da condutância estomática e transpiração das enxertias not/not, Luk/not e pen/not (Figura 1) foi similar ao observado por Jones et al. (1987) em enxertias de $L$. esculentum com os mutantes deficientes em ABA notabilis, flacca, e sitiens; Fambrini et al. (1995) em enxertias de um genótipo selvagem de girassol com 
um mutante deficiente em ABA, e Holbrook et al. (2002) em enxertias de L. esculentum com os mutantes flacca e sitiens. Em todos estes trabalhos o comportamento estomático das enxertias foi determinado principalmente pelo genótipo da copa, fato que está indicando que o ABA sintetizado pela parte aérea deveria ser transportado à raiz para desempenhar a função como sinalizador.
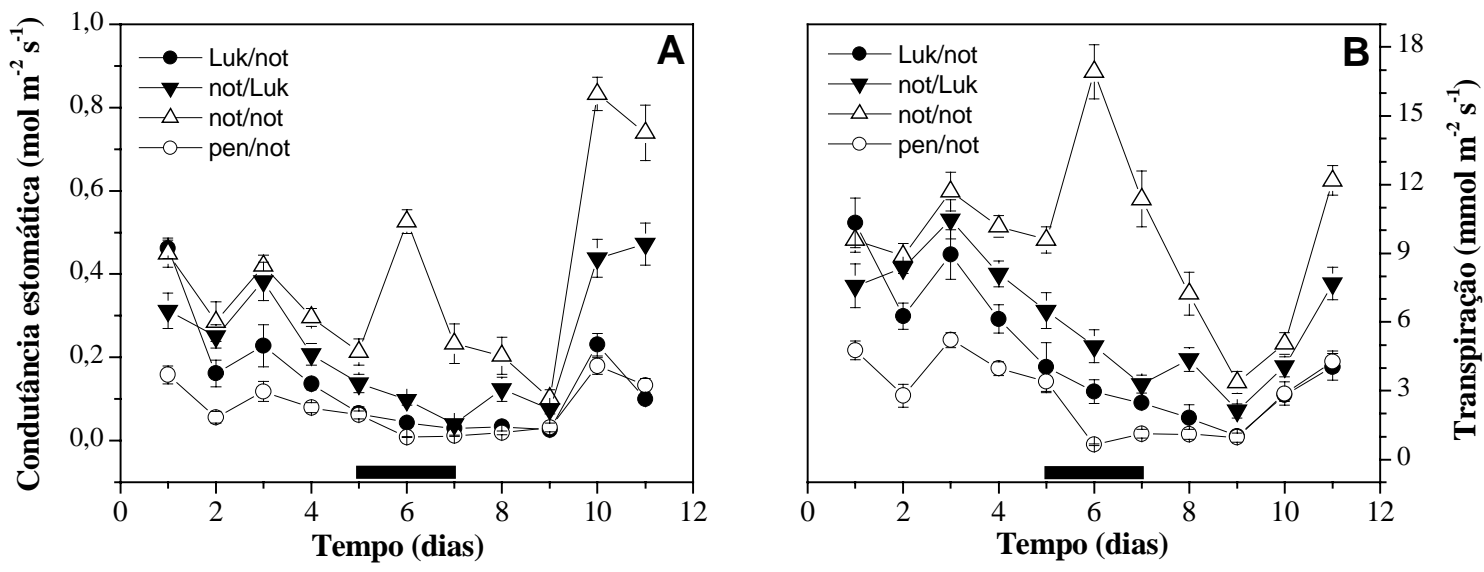

Figura 1 -Condutância estomática (A) e transpiração (B) em enxertias Lukullus/notabilis (Luk/not), notabilis/Lukullus (not/Luk), notabilis/notabilis (not/not) e pennellii/notabilis (pen/not) submetidas a estresse hídrico imposto pela suspensão da irrigação durante 3 dias (indicados por barra horizontal escura). Pontos representam valor médio de 3 repetições e linhas verticais o erro padrão da média

O transporte do ABA através do floema e sua recirculação pelo xilema foi constatado por Loveys (1984), quem mediante aplicação foliar de ABA marcado isotopicamente e cromatografia líquida, demonstrou que o ABA presente na raiz de plantas de videira foi fornecido em maior quantidade pela parte aérea. A eliminação do caule levou a uma rápida diminuição na concentração de ABA no xilema, confirmando assim a necessidade da parte aérea para garantir uma adequada quantidade de ABA nas plantas. 
Wolf et al. (1990) empregando técnicas imunológicas (ELISA) para determinar a concentração de ABA sintetizado tanto na parte aérea quanto na raiz de Lupinus albus, em condições de estresse salino, verificaram que somente $28 \%$ do ABA encontrado no xilema foi sintetizado pela raiz e a quantidade restante correspondeu ao ABA recirculado proveniente da parte aérea.

Cornish e Zeevaart (1985) avaliaram o efeito do estresse hídrico na concentração de ABA na raiz de Xanthium strumarium e L. esculentum, e constataram que tanto em condições ótimas de irrigação como de deficiência hídrica, a quantidade de ABA presente nas folhas de ambas espécies foi significativamente maior que nas raízes, embora em condições de deficiência hídrica ocorreu um maior aumento da síntese de ABA nas raízes.

Os valores médios de condutância estomática e transpiração da enxertia pen/not em condições iniciais de disponibilidade hídrica, foram menores do que os observados nas enxertias not/not, not/Luk e Luk/not (Figura 1), o que parece indicar que as características morfo-anatômicas que L pennellii possui contribuíram na melhora do controle estomático. Kebede et al. (1994) estudando a relação existente entre a anatomia foliar e o comportamento estomático de $L$. esculentum e $L$. pennellii, verificaram que $L$. pennellii apresentou menor condutância estomática que L. esculentum, resposta que atribuíram ao fato de $L$. pennellii ter folhas $54 \%$ mais espessas e com uma freqüência estomática $29 \%$ menor que $L$. esculentum.

A condutância estomática e transpiração da enxertia not/Luk quando comparada com a observada na enxertia not/not no período sem irrigação (Figura 1), parece indicar que aconteceu uma recuperação parcial do controle estomático, situação na que o ABA sintetizado principalmente por Lukullus estaria facilitando a sinalização necessária entre raiz e parte aérea.

Mudanças fenotípicas o como desaparecimento do aspecto murcho e aumento em crescimento foram observadas por Cornish e Zeevaart (1988) em enxertias de flacca e sitiens sobre $L$. esculentum, fato que estaria indicando que o ABA sintetizado pelo porta-enxerto contribuiu para um melhor controle estomático. Por outro lado, Jones et al. (1987), Fambrini et al. (1995) e Holbrook et al. (2002), em trabalhos já mencionados, 
relataram que enxertias de mutantes deficientes em ABA sobre porta-enxertos com capacidade normal de síntese de ABA, apresentam menor condutância estomática do que as enxertias dos mutantes sobre porta-enxertos do mesmo genótipo, o que concorda plenamente com os resultados obtidos no presente trabalho e confirma a importância relativa do ABA sintetizado na raiz.

Em condições de deficiência hídrica a enxertia not/not atingiu valores de condutância estomática e transpiração significativamente maiores que as enxertias not/Luk e Luk/not (Figura 1), comportamento que evidencia ausência de adequado controle estomático na enxertia not/not como conseqüência da deficiente síntese de ABA que caracteriza a mutação notabilis. Neill e Horgan (1985) estabeleceram que em condições irrigadas o conteúdo de ABA em notabilis correspondeu a 49\% da quantidade presente em plantas não mutantes de L. esculentum. Estes autores também observaram que um aumento equivalente a três vezes a quantidade basal de ABA ocorreu em notabilis após 72 horas de deficiência hídrica, enquanto no genótipo não mutante o mesmo aconteceu em apenas 24 horas.
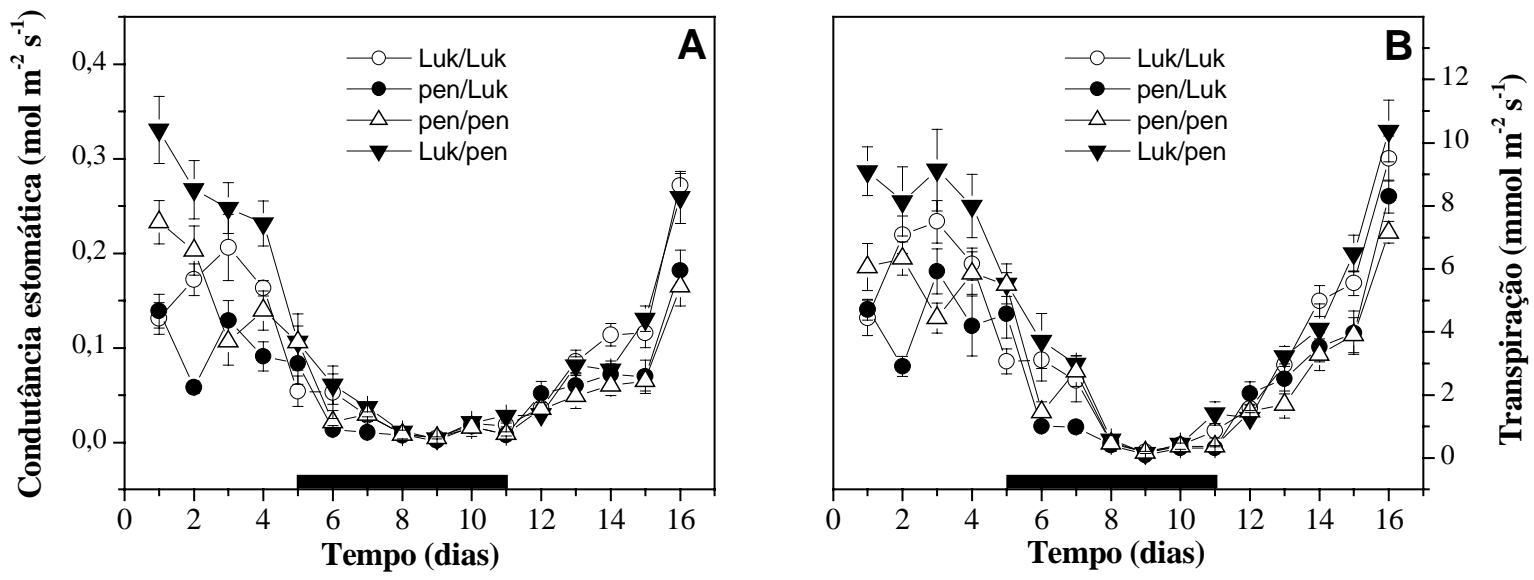

Figura 2 - Condutância estomática (A) e transpiração (B) em enxertias Lukullus/Lukullus (Luk/Luk), pennellii/Lukullus (pen/Luk), pennellii/pennellii (pen/pen) e Lukullus/pennellii (Luk/pen) submetidas a estresse hídrico imposto pela suspensão da irrigação durante 7 dias (indicados por barra horizontal escura). Pontos representam valor médio de 3 repetições e linhas verticais o erro padrão da média 
As enxertias Luk/Luk e pen/pen apresentaram um comportamento estomático similar em condições de deficiência hídrica (Figura 2), este resultado sugere que embora os genótipos Lukullus e L. pennellii apresentem mecanismos de resposta à deficiência hídrica diferentes (Cornish e Zeevaart, 1985; Fobes et al., 1985; Pillay e Beyl, 1990; Kebede et al., 1994), o efeito produzido por estes mecanismos sobre a condutância estomática e transpiração poderia ser semelhante. Segundo Parker e Pallardi (1985), a resposta das plantas à deficiência hídrica é a expressão integrada de características fisiológicas, morfológicas e anatômicas. A partir do segundo dia de reirrigação a enxertia pen/pen atingiu menores valores de condutância estomática e transpiração que a enxertia Luk/Luk, fato que concorda com o observado por Torrecillas et al. (1995) em um estudo comparativo das relações hídricas e capacidade de recuperação de L. pennellii e L. esculentum sob déficit hídrico.

A comparação da condutância estomática e transpiração das enxertias Luk/Luk e Luk/pen, pen/pen e pen/Luk (Figura 2) permite estabelecer que durante o período de deficiência hídrica e reidratação, os porta-enxertos dos genótipos Lukullus e L. pennellii influenciaram de modo semelhante o comportamento estomático destas enxertias. A literatura relata que em condições de deficiência hídrica em L. pennellii ocorreu diminuição da quantidade de citocinina presente na raiz (Pillay e Beyl, 1990), enquanto em L. esculentum aconteceu aumento da quantidade de ABA na raiz (Cornish e Zeevaart, 1985). Portanto, pode ser que sinais químicos provenientes da raiz de Lukullus e L. pennellii embora de natureza química diferente, possam ter efeito semelhante na regulação estomática das enxertias.

As enxertias Luk/Luk e pen/Luk, pen/pen e Luk/pen (Figura 2) apesar de possuírem a parte aérea de diferente genótipo, durante o período de deficiência hídrica comportaram-se de maneira semelhante com relação a condutância estomática e transpiração. L. pennellii tem caracteres morfo-anatômicos na folha que lhe permitem tolerância à seca (Kebede et al., 1994) e L. esculentum apresenta uma alta quantidade de ABA na parte aérea (Cornish e Zeevaart, 1985). Estas características dos genótipos embora diferentes, possivelmente influenciaram de modo semelhante o padrão de 
resposta da condutância estomática e transpiração das enxertias em condições de deficiência hídrica.

A tendência de resposta da condutância estomática e transpiração apresentada pelas enxertias pen/Luk (Figura 3A-B) e Luk/Luk (Figura 3C-D) submetidas a deficiência quando comparada com a observada em seus respectivos controles, mostra que houve uma resposta relativamente rápida frente ao déficit hídrico. De maneira contrária, a reirrigação não permitiu a recuperação imediata da condutância estomática, fato que sugere que o controle estomático dessas enxertias é determinado por um mecanismo hidroativo. Em tal situação a abertura estomática poderia ser impedida pelo efeito persistente do ABA sintetizado durante o período de deficiência hídrica (Fisher et al., 1970). Este mecanismo garantiria a ascensão de água por pressão radicular, o que é mais vantajoso do que a transpiração para realcançar a turgescência.

De modo diferente das enxertias onde os porta-enxertos possuíam a capacidade de sintetizar ABA(Figura 3), nos tratamentos pen/not e Luk/not (Figura 4) não houve diferença na condutância estomática entre o controle e as enxertias sob estresse, quando foi retomada a irrigação. Esses dados sugerem que o ABA sintetizado nas raízes é responsável pelo mecanismo hidroativo que mantem os estômatos fechados após a reirrigação.

Embora em condições de deficiência hídrica não tenha existido diferença estatística na condutância estomática da enxertia pen/not sempre irrigada e submetida a estresse hídrico (Figura 4A-B), a taxa de transpiração das plantas não irrigadas foi inferior à observada no controle no segundo e terceiro dia de deficiência hídrica, o que sugere que fatores não estomáticos e talvez associados à cutícula puderam reduzir a perda de água por transpiração.

Segundo Larcher (2000), plantas que são submetidas a deficiência hídrica no solo ou na atmosfera possuem folhas com uma cutícula mais espessa do que as plantas da mesma espécie em condições de disponibilidade hídrica adequada. De acordo com Taiz e Zeiger (1998), o espessamento da cutícula é facilitado pelo aumento na síntese de lipídios. 

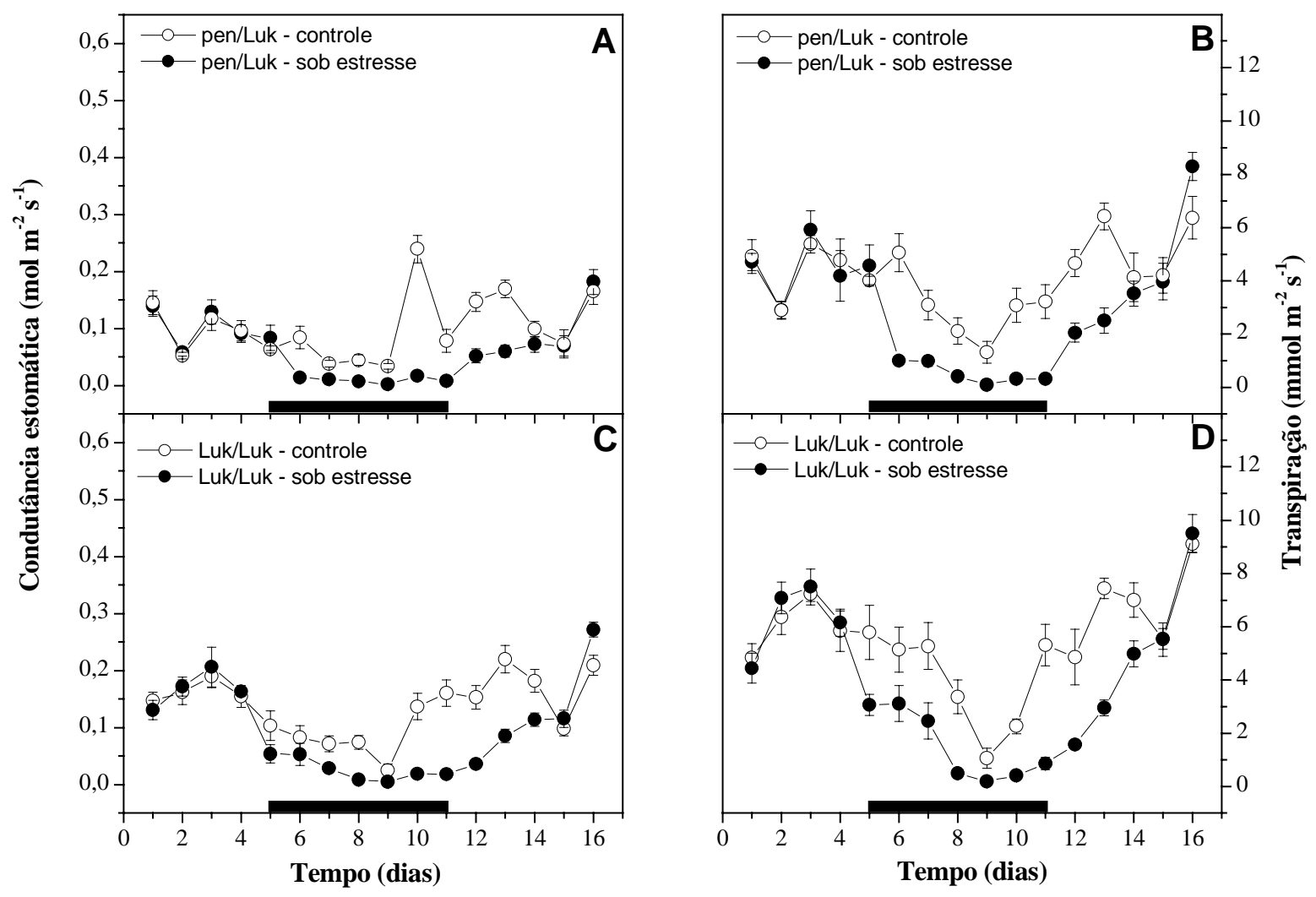

Figura 3 - Condutância estomática (A e C) e transpiração (B e D) em enxertias pennellii/Lukullus (A e B) e Lukullus/Lukullus (C e D) irrigadas (círculos claros) e sob estresse hídrico (círculos escuros) imposto pela suspensão da irrigação durante 7 dias (indicados por barra horizontal escura). Pontos representam valor médio de 3 repetições e linhas verticais o erro padrão da média 

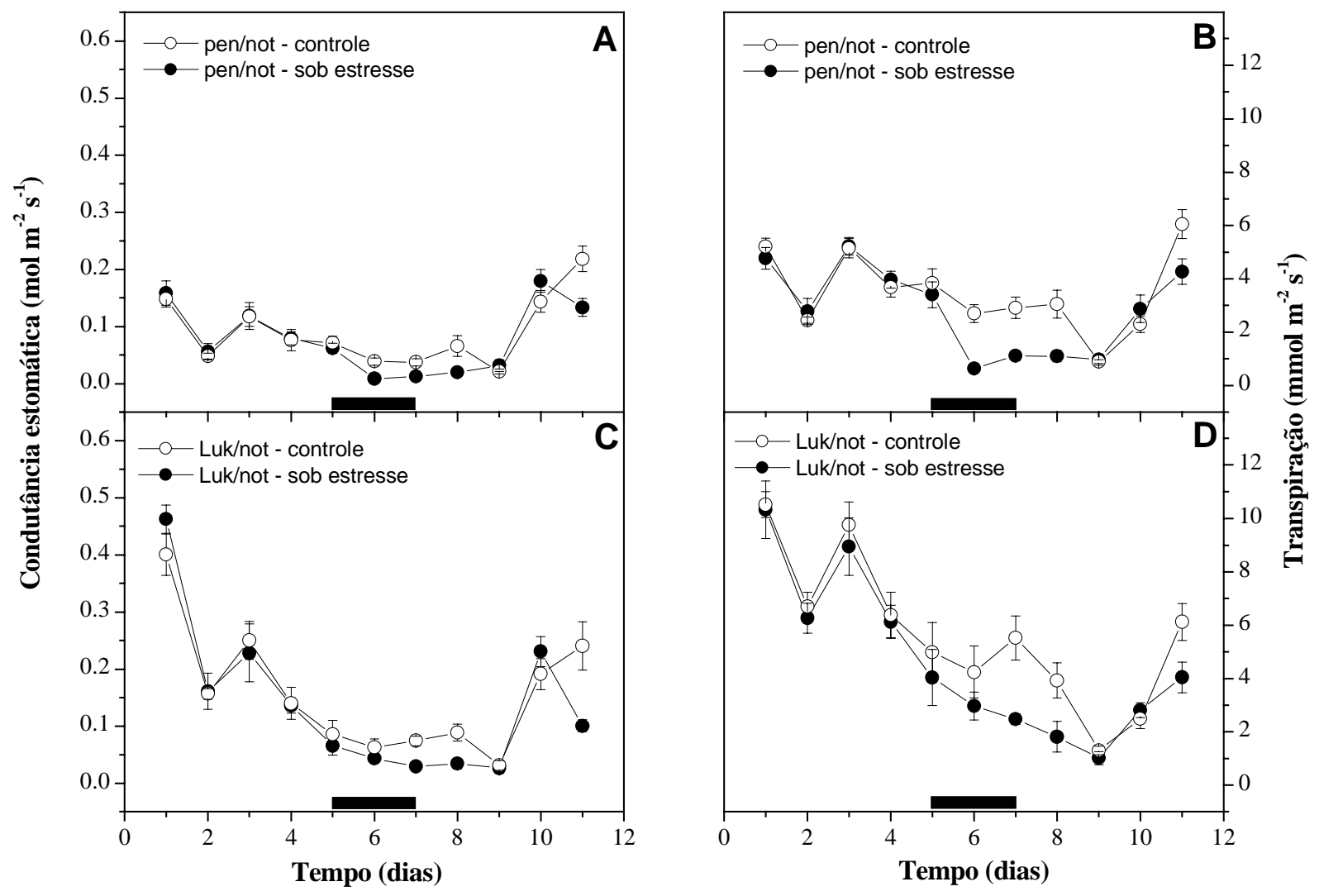

Figura 4 - Condutância estomática (A e C) e transpiração (B e D) em enxertias pennellii/notabilis (A e B) e Lukullus/notabilis (C e D) irrigadas (círculos claros) e sob estresse hídrico (círculos escuros) imposto pela suspensão da irrigação durante 3 dias (indicados por barra horizontal escura). Pontos representam valor médio de 3 repetições e linhas verticais o erro padrão da média 
Fobes et al. (1985) empregando técnicas cromatográficas estudaram a acumulação de lipídeos na superfície foliar de L. pennellii e L. esculentum. Estes autores verificaram que em L. esculentum $0,96 \%$ do peso seco foliar correspondeu a lipídeos, enquanto em L. pennellii a quantidade de lipídeos foi equivalente a 19,9\% do peso seco foliar. Baseados nestes resultados, Fobes et al. (1985) sugeriram que a acumulação de lipídeos os quais são constituintes da cutícula, em L. pennellii poderia ser um mecanismo de tolerância à seca.

\subsubsection{Potencial da água na folha}

Observa-se (Tabela 4) que em condições de deficiência hídrica, os menores valores de potencial da água na folha foram atingidos por enxertias com parte aérea do genótipo Lukullus (Luk/Luk e Luk/pen). Este resultado concorda com os relatados por Alarcón et al. (1993) e Torrecillas et al. (1995), os quais verificaram que sob condições de estresse L. esculentum apresentou menores valores de potencial da água quando comparado com L. pennellii, os autores sugeriram que isto foi conseqüência de ajustamento osmótico. Segundo Chandler e Robertson (1994) e Plant e Bray (1999) a síntese de substâncias que permitem a tolerância ao estresse é controlada por genes, cuja expressão pode ser regulada por mudanças na concentração de ABA que acontecem em condições de estresse.

Estudos realizados por Bray (1988), Cohen e Bray (1990) e Plant et al. (1991) com L. esculentum estabeleceram uma estreita relação entre a concentração de ABA em condições de deficiência hídrica e a expressão de alguns genes, que possivelmente estariam envolvidos na síntese de substâncias que facilitam a tolerância à seca. Portanto, nas enxertias Luk/Luk e Luk/pen em condições de deficiência hídrica pode ter acontecido ajustamento osmótico promovido por síntese incrementada de ABA, o que permitiu a estas enxertias atingir valores baixos de potencial da água. 
Tabela 4. Valores de potencial da água na folha $\left(\Psi_{\mathrm{f}}\right)$ medidos antes do amanhecer em enxertias de genótipos de Lycopersicon irrigadas e submetidas a estresse hídrico

\begin{tabular}{cccc}
\hline \multirow{2}{*}{ Enxertia } & Irrigado & Máximo estresse* & $\begin{array}{c}\text { Número de dias } \\
\text { Suportados sob } \\
\text { deficiência hídrica }\end{array}$ \\
\cline { 2 - 3 } Luk/Luk & $\Psi_{\mathrm{f}}(\mathrm{MPa})$ & $\Psi_{\mathrm{f}}(\mathrm{MPa})$ & 7 \\
not/Luk & $-0,70$ & $-2,06$ & 3 \\
pen/Luk & $-0,82$ & $-1,46$ & 7 \\
not/not & $-0,43$ & $-1,46$ & 3 \\
Luk/not & $-0,91$ & $-1,46$ & 3 \\
pen/not & $-0,75$ & $-1,40$ & 3 \\
pen/pen & $-0,40$ & $-0,80$ & 7 \\
Luk/pen & $-0,44$ & $-1,33$ & 7 \\
\hline
\end{tabular}

* Máximo estresse: dia no qual as plantas atingiram a condutância estomática próxima de zero.

As enxertias pen/Luk e pen/pen embora tenham sido submetidas a um tempo igual de deficiência hídrica comparado às enxertias Luk/Luk e Luk/pen, não atingiram valores de potencial da água tão baixos como os observados nestas (Tabela 4). Este fato parece indicar que enxertias com L. pennellii como parte aérea possuem melhor controle estomático. Segundo Chaves (1991), o controle estomático é de fato uma das primeiras linhas de defesa contra a dessecação e permite manter altos valores de potencial da água por períodos prolongados de seca. Trabalhos realizados por Pillay e Beyl (1990), Alarcón et al. (1993) e Torrecillas et al. (1995), já mencionados anteriormente, mostram que em L pennellii sob condições de estresse, altos valores de potencial da água na folha estiveram associados a reduzida condutância estomática. 


\subsection{EXPERIMENTO II}

A aplicação foliar de ABA $(10 \mu \mathrm{M})$ permitiu que de doze enxertias feitas com notabilis como parte aérea e L. pennellii como porta-enxerto sobrevivessem três enxertias.

Os resultados do experimento realizado empregando plantas de notabilis, $L$. pennellii e enxertias de notabilis com L. pennellii como porta-enxerto (Tabela 5), permitiram constatar que notabilis apresenta baixa capacidade de sobrevivência em condições de limitada disponibilidade hídrica. Ao contrário, L. pennellii apresenta um alto grau de tolerância a deficiência hídrica, atributo que ao parecer não é determinado de maneira exclusiva por caracteres morfo-anatômicos que esta planta possui, já que observações prévias feitas por Pillay e Beyl (1990) indicam que sinais de tipo hormonal participam na regulação do comportamento estomático desta espécie. Estes autores avaliando as respostas imediatas causadas por déficit hídrico em plantas de L. pennellii, L. chilense e L. esculentum, verificaram que depois de 24 horas de imposição de deficiência hídrica L pennellii apresentou mudanças mínimas no potencial da água, menor taxa de transpiração e por coincidência uma marcada diminuição no nível de citocinina na raiz, em comparação com L. chilense e L. esculentum.

De acordo a literatura (Zhang et al., 1987; Gowing et al., 1990; Khalil e Grace, 1993) não se descarta a possibilidade que o ABA esteja envolvido na regulação estomática de $L$. pennelli ou que uma interação citocinina-ABA desempenhe a função como sinalizador químico em condições de deficiência hídrica, fato que foi constatado em arroz por Bano et al. (1993). Estes autores observaram que em plantas de arroz a imposição de déficit hídrico levou a uma queda na condutância estomática, a qual esteve acompanhada por um aumento na quantidade de ABA presente no xilema e uma diminuição no conteúdo de citocinina. De maneira contrária, após a reirrigação das plantas foi verificado um incremento na condutância estomática, um decréscimo no nível de $\mathrm{ABA}$ e um aumento na quantidade de citocinina no xilema. Resultados similares também foram obtidos por Shashidhar et al. (1996) trabalhando com girassol. 
A alta capacidade de sobrevivência observada na enxertia not/pen em condições de deficiência hídrica, sugere que sinais de natureza química originadas na raiz de L. pennellii contribuíram de forma significativa para a melhora do controle estomático de notabilis, condição que permitiu às enxertias reduzir a perda de água por transpiração. Os relatos da literatura considerados anteriormente, levam a crer que no processo de sinalização química pode ter acontecido alguma mudança no nível de citocinina, ABA ou em conjunto dos dois hormônios. 

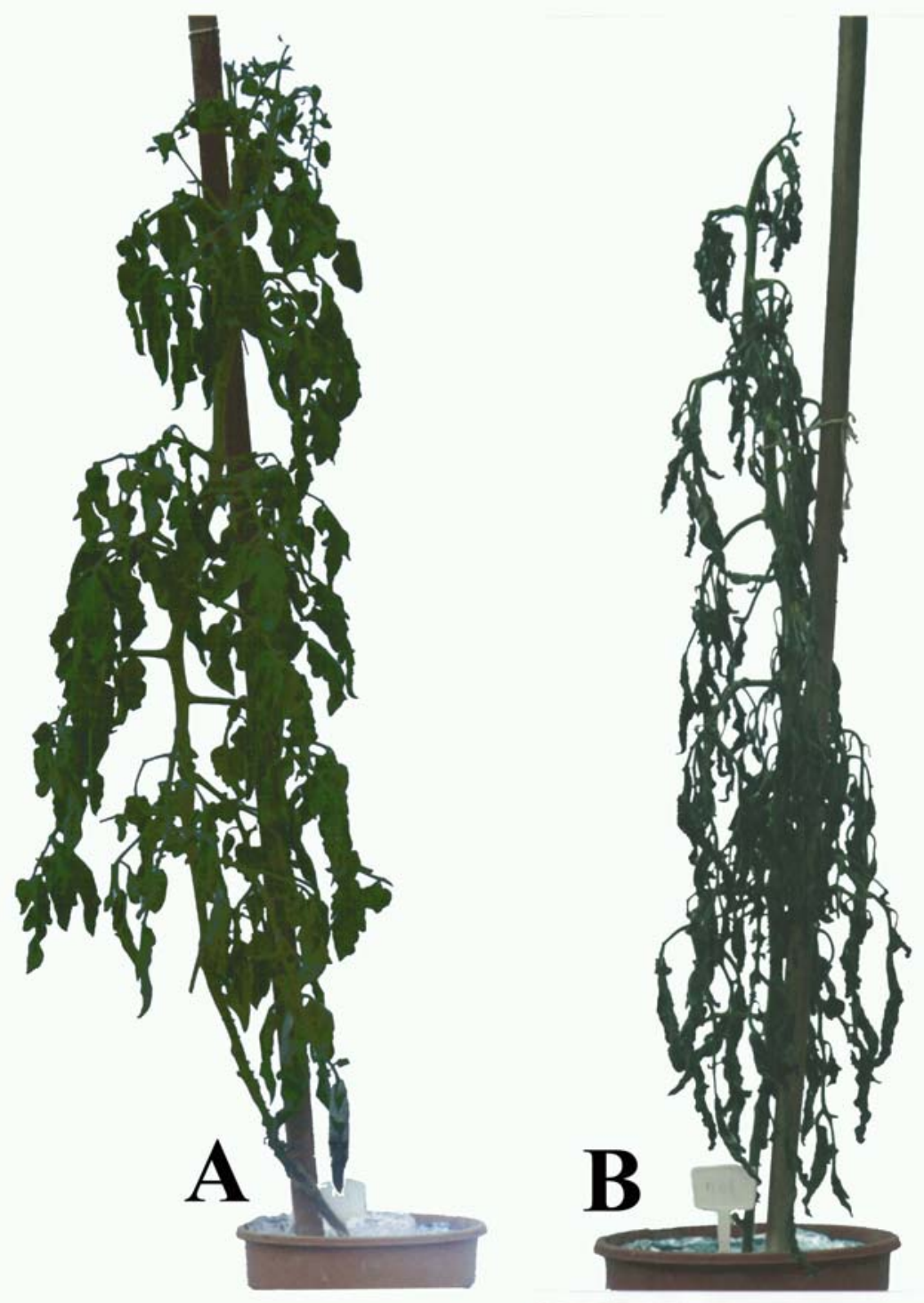

Figura 5 - Aspecto visual de uma planta da enxertia notabilis/pennellii (A) e uma planta notabilis sem enxertia (B) após 4 dias de estresse hídrico imposto pela suspensão da irrigação

Tabela 5. Tempo decorrido para alcançar a murcha permanente em plantas do genótipo Lycopersicon sob deficiência hídrica imposta por suspensão da irrigação

\begin{tabular}{cccc}
\hline Planta & notabilis* & L. pennellii & not/pen** \\
\cline { 2 - 4 } Dias & 5 & 27 & 21
\end{tabular}

* mutante notabilis de L. esculentum; **not/pen: notabilis/pennellii. 


\section{CONCLUSÕES}

O ácido abscísico sintetizado na parte aérea de Lycopersicon esculentum pode atuar como sinal hormonal que permite a sobrevivência da planta em condições de deficiência hídrica.

Em Lycopersicon pennellii a tolerância a seca não é determinada de maneira exclusiva por caracteres morfo-anatômicos. 


\section{REFERENCIAS BIBLIOGRÁFICAS}

ALARCÓN, J.J.; SÁNCHEZ-BLANCO, M.J.; BOLARÍN, M.C.; TORRECILLAS, A. Water relations and osmotic adjustment in Lycopersicon esculentum and L. pennellii during short-term salt exposure and recovery. Physiologia Plantarum, v. 89, n.3, p. 441-447, 1993.

ASSMANN, S.M.; SHIMAZAKI, K.L. The multisensory guard cell, stomatal responses to blue light and abscisic acid. Plant Physiology, v.119, n.3, p.809-816, 1999.

AZCON-BIETO, J.; TALON, M. Fisiología y bioquímica vegetal. Madrid: Interamericana, McGraw-Hill, 1996. 581p.

BANO, A.; DÖRFFLING, K.; BETTIN, D.; HAHN, H. Abscisic acid and cytokinins as possible root-to-shoot signals in xylem sap of rice plants in drying soil. Australian Journal of Plant Physiology, v.20, n.1, p. 109-115,1993.

BRAY, E.A. Drought- and ABA- induced changes in polypeptide and mRNA accumulation in tomato leaves. Plant Physiology, v.88, n.4, p. 1210-1214, 1988.

BRAY, E.A. Abscisic acid regulation of gene expression during water-deficit stress in the era of the Arabidopsis genome. Plant Cell and Environment, v.25, n.1, p.153161, 2002.

CHANDLER, P.M.; ROBERTSON, M. Gene expression regulated by abscisic acid and its relation to stress tolerance. Annual Review of Plant and Molecular Biology, v. 45, p. 113-141, 1994.

COHEN, A.; BRAY, E.A. Characterization of three mRNAs that accumulate in wilted tomato leaves in response to elevated levels of endogenous abscisic acid. Planta, v. 182, n.1, p. 27-33, 1990. 
CORNISH, K.; ZEEVAART, J.A. Abscisic acid accumulation by roots of Xanthium strumarium L. and Lycopersicom esculentum Mill. in relation to water stress. Plant Physiology, v. 79,n.3, p. 653-658, 1985.

CORNISH, K.; ZEEVAART, J.A. Phenotypic expression of wild-type tomato and three wilty mutants in relation to abscisic acid accumulation in roots and leaflets of reciprocal grafts. Plant Physiology, v. 87,n.1, p. 190-194, 1988.

CUMMINS W.R.; KENDE H.; RASCHKE K. Specificity and reversibility of the rapid stomatal response to abscisic acid. Planta, v.99,n.3, p. 347-351, 1971.

DAVIES, W.J.; ZHANG, J. .Root signal and the regulation of growth and development of plant in drying soil. Annual Review of Plant Physiology and Plant Molecular Biology, v. 42, p.55-76, 1991.

DAVIES, W.J.; WILKINSON, S.; LOVEYS, B. Stomatal control by chemical signalling and the exploitation of this mechanism to increase water use efficiency in agriculture. New Phytologist, v.153,n.3, p. 449-460, 2002.

DUCKHAM, S. C.; TAYLOR I.B..; LINFORD, R. J.; AL-NAIEB, B.A.; MARPLES, B.A. ; BOWMAN, W.R. The metabolism of cis ABA-aldehyde by the wilty mutants of potato, pea and Arabidopsis thaliana. Journal of Experimental Botany, v. 40, n.217, p. 901-905,1989.

ESQUINAS-ALCAZAR, J.; NUEZ, F. Situación taxonómica, domesticación y difusión del tomate. In: NUEZ, F. (Ed.) El Cultivo del tomate. Madrid: Ediciones MundiPrensa, 2001. p. 13-42.

FAMBRINI, M.; VERNIERI, P.;TONCELLI, M.; ROSSI, V.; PUGLIESI, C. Characterization of a wilty sunflower (Helianthus annuus L.) mutant. III. Phenotypic interation in reciprocal grafts from wilty mutant and wild-type plants. Journal of Experimental Botany, v. 46, n.286, p. 525-530, 1995.

FISHER, R.A.; HSIAO, T.C.; HAGAN, R. M. After-effect of water stress on stomatal opening potencial.I. Techniques and magnitudes. Journal of Experimental Botany, v.21, n.67, p.371-385,1970. 
FOBES, J.; MUDD, J.; MARSDEN, M. Epicuticular lipid accumulation on the leaves of Lycopersicon pennellii (Corr.) D'Arcy and Lycopersicon esculentum Miil. Plant Physiology, v.77, n. 3, p. 567-570, 1985.

GOWING, D.J.; DAVIES, W.J.; JONES, H.G. A positive root-sourced signal as an indicator of soil drying in apple, Malus $x$ domestica Borkh. Journal of Experimental Botany, v.41, n.233, p.1535-1540, 1990.

HARRIS, M. J. ; OUTLAW, W.H. Rapid adjusment of guard-cell abscisic acid levels to current leaf water staus. Plant Physiology, v.95, n.1, p.171-173,1991.

HARTUNG, W. The site of action of abscisic acid at the guard cell plasmalemma of Valerianella locusta. Plant Cell and Environment, v.6, n.4, p.427-428,1983.

HETHERINGTON, A.M.; QUATRANO, R. S. Mechanism of action of abscisic acid at the celular level. New Phytologist, v.119, n.1, p.9-32,1991.

HOLBROOK, N.M.; SHASHIDHAR, V.R.; JAMES, R.; MUNNS, R. Stomatal control in tomato with ABA-deficient roots: response of grafted plants to soil drying. Journal of Experimental Botany, v. 53, n.373, p. 1503-1514, 2002.

JONES, H.G.; SHARP, C.S.; HIGGS, K.H. Growth and water relations of wilty mutants of tomato (Lycopersicon esculentum Mill.). Journal of Experimental Botany, v. 38, n.196, p. 1848-1856, 1987.

JONES, R. J.; MANSFIELD T.A. Suppression of stomatal opening in leaves treated with abscisic acid. Journal of Experimental Botany, v.21, n.68, p. 714-719, 1970.

KEBEDE, H.; MARTIN, B.; NIENHUIS, J.; KING, G. Leaf anatomy of two Licopersicom species with contrasting gas exchange properties. Crop Science, v.34, n.1, p.108-113,1994.

KEITH, A. Is abscisic aldehyde really the immediate precursor to stress-induced ABA?.Trends in Plant Science, v.5, n.5, p.191-192, 2000.

KHALIL, A.; GRACE, J. Does xylem sap ABA control the stomatal behaviour of water-stressed sycamore (Acer pseudoplatanus L.) seedlings? Journal of Experimental Botany, v. 44, n. 264, p. 1127-1134, 1993. 
LAGRIMINI, L.M.; JOLY, R. J.; DUNLAP, J.R.; LIU, T.Y. The consequense of peroxidase overexpression in transgenic plants on root growth and development. Plant Molecular Biology, v. 33, n. 4, p. 887-895, 1997.

LARCHER, W. Ecofisiologia vegetal. São Paulo: Rima Artes e Textos, 2000. 531p.

LINFORTH, R. S.; BOWMAN, W. R.; GRIFFIN, D.A.; MARPLES, B.A.; TAYLOR, I.B. 2-trans-ABA-alcohol accumulation in the wilty tomato mutants flacca and sitiens. Plant Cell and Environment, v.10, n.5, p.599-606,1987.

LOVEYS, B.R. Abscisic acid transport and metabolism in grapevine (Vitis vinifera L.). New Phytologist, v. 98, n.4, p. 575-582, 1984.

NEILL, S.J.; HORGAN, R. Abscisic acid production and water relations in wilty tomato mutants subjected to water deficiency. Journal of Experimental Botany, v. 36, n.169, p.1222-1231, 1985.

PARKER, W.C.; PALLARDY, S.J. genotypic variation in tissue water relations of leaves and roots of black walnut (Juglans nigra) seedlings. Physiologia Plantarum, v. 64, n. 1, p. 105-110, 1985.

PARRY, A.D.; NEILL, S.J.; HORGAN, R. Xanthoxin levels and metabolism in the wild-type and wilty mutants of tomato. Planta, v.173, n.3, p.397-404,1988.

PILLAY, I.; BEYL, C. Early responses of drought-resistant and susceptible tomato plants subjeted to water stress. Plant Growth Regulation, v.9, n. 1, p. 213-219, 1990.

PLANT, A.; BRAY, E. Regulation of gene expression by abscisic acid during environmental stress. In: LERNER, H.R. (Ed.) Plant responses to environmental stresses from phytohormones to genome reorganization. New York: Marcel Dekker, 1999.p. 303-331.

PLANT, A. L.; COHEN, A.; MOSES, M.; BRAY, E. Nucleotide sequence and spatial expression pattern of a drought- and abscisic acid-induced gene of tomato. Plant Physiology, v. 97, n.3, p. 900-906, 1991.

ROCK, C.D.; HEATH, T.G.; GAGE, D.A.; ZEEVAART, J.A. Abscisic-alcohol is an intermediate in abscisic acid (ABA ) biosynthesis in a shunt pathway from abscisic aldehyde. Plant Physiology, v. 97, n.2, p.670-676,1991. 
SCHWARTZ, S.H.; QIN X.; ZEEVAART, J.A. Elucidation of the indirect pathway of abscisic acid biosynthesis by mutants, genes, and enzymes. Plant Physiology, v.131, n.4, p.1591-1601, 2003.

SHASHIDHAR, V.; PRASAD, T.; SUDHARSHAN. Hormone signals from roots to shoots of sunflower (Helianthus annus L.). Annals of Botany, v. 78, n. 2, p. 151-155, 1996.

STUART, D.; WILKINSON, S.; BACON, M.A.; DAVIES, W.J. Multiple signals and mechanisms that regulate leaf growth and stomatal behaviour during water deficit. Physiologia Plantarum, v.100, n.2, p.303-313, 1997.

TAIZ, L.; ZEIGER, E. Plant Physiology. Massachusetts. Sinauer Associates, Publishers, 1998.792p.

TAL, M. Abnormal stomatal behavior in wilty mutants of tomato. Plant Physiology, v.41, n.2, p.1387-1391,1966.

TAYLOR, I.B. Biosystematics of the tomato. In: ATHERTON, J.; RUDICH, J. (Ed.) The tomato crop. London: Chapman \& Hall, 1986.p. 1-34.

THOMPSON, A.J.; JACKSON, A.C.; SYMONDS, R.C.; MULHOLLAND, B.J.; DADSWELL, A.R.; BLAKE, P.S.; BURBIDGE, A.; TAYLOR, B. Ectopic expression of a tomato 9-cis-epoxycarotenoid dioxygenase gene causes overproduction of abscisic acid. The plant Journal, v.23, n.3, p.363-374, 2000.

TORRECILlAS, A.; GUILLAUME, C.; ALARCON, J..J.; RUIZ-SANCHEZ, M.C. Water relations of two tomato species under water stress and recovery. Plant Science, v.105, n.2, p.169-176,1995.

WARNOCK, S.J. A review of taxonomy and phylogeny of the genus Lycopersicon. HortScience, v. 23, n. 4, p. 669-973, 1988.

WILKINSON, S.; DAVIES, W.J. Xylem sap pH increase: A drought signal received at the apoplastic face of the guard cell that involves the suppression of saturable abscisic acid uptake by the epidermal symplast. Plant Physiology, v.113, n.2, p.559$573,1997$. 
WOLF, O.; JESCHKE, W.D.; HARTUNG, W. Long distance transport of abscisic acid in NaCl-treated intact plants of Lupinus albus. Journal of Experimental Botany, v. 41, n.226, p. 593-600, 1990.

ZEEVAART, J.A.; CREELMAN R.A. Metabolism and physiology of abscisic acid. Annual Review of plant Physiology and molecular Biology, v.39, p.439-473, 1988. ZHANG, J.; SCHURR, U.; DAVIES, W.J. Control of stomatal behaviour by abscisic acid which apparently originates in the roots. Journal of Experimental Botany, v.38, n.192, p. 1174-1181, 1987. 